\title{
Leadership Development in Tight Times: Scaling up courses without water- ing them down
}

\section{Mr. Chris Carlson-Dakes, University of Wisconsin, Madison}

Dr. Carlson-Dakes is a faculty associate in the College of Engineering at the University of WisconsinMadison and is on the faculty in the School of Business at Edgewood College in Madison, Wisc. He has industry experience as director of Organizational Development for an architectural engineering firm where he worked at an executive leadership level on individual and group leadership development. Dr. Carlson-Dakes' formal training in technical disciplines, and his personal passion for bringing a balanced approach to life allow him to combine highly technical curriculum with social, political, environmental, and emotional issues into a blended pedagogy needed for developing leaders of the future. His combined experience in academia, industry, and international teaching and consulting bring a strong blend of diverse real world perspectives into the classroom. Dr. Carlson-Dakes has Mechanical Engineering degrees from Carnegie Mellon University and Penn State University, and a doctoral degree in Socio-Technical Systems Industrial Engineering from the University of Wisconsin-Madison.

\section{Gregory W Harrington, Dept of Civil \& Environmental Engineering, Univ of Wisconsin - Madison}

Greg Harrington is a professor in the Department of Civil and Environmental Engineering at the University of Wisconsin, where he has been since 1996. His research and teaching interests primarily involve drinking water treatment, distribution, and regulatory policy. He is currently the department's associate chair for the undergraduate program and the Suzanne \& Richard Pieper Family Foundation Servant leader chair for the university's College of Engineering. 


\title{
Leadership development in tight times: Expanding our educational reach without watering it down
}

\begin{abstract}
This paper addresses a challenge many universities face: How can we meet increasing demands for undergraduate leadership development during a time of dwindling resources? Our alumni and industry partners tell us we need to graduate students with more leadership experience - yet we encounter a confluence of conflicting factors that make it difficult to respond accordingly. Leadership development is a long-term process in which students benefit from early and ongoing engagement throughout college. Recommendations by the National Academy of Engineering reinforce educational research that shows learning is enhanced by smaller classes, more direct contact with instructors, and active engagement in real world projects. Yet we struggle to find feasible paths to take action. Pressures to increase enrollment and cut budgets challenge us to find ways to do more with less without diluting the learning experience. Administrators embrace the need to update curriculum to remain current and relevant, yet there is no room to add in a tightly packed four-year program. These tensions require innovative approaches to engineering education and leadership development to meet the challenges of the future.
\end{abstract}

\section{Introduction - An Overall Framework}

There is general agreement that a renewed focus on leadership development is critical to the future success of the engineering discipline (NAE 2004). Our thinking begins to diverge, however, when we discuss why we face this need, who needs to act, what needs to be done, and how we can begin to take action.

This paper offers one curricular model as a point of intervention that has shown early success in preparing leaders at a large public research university while remaining mindful of our national trend toward increasing enrollments and decreasing budgets. The paper ends with lessons learned and guidelines for how to expand and adapt this model at other institutions.

There are numerous pockets of activity and local champions of leadership development efforts on many campuses. Overall, however, our collective efforts have been inadequate to respond accordingly with regard to how we cultivate, identify, and intentionally develop engineering leaders of the future. As engineering faculty, the challenge in front of us to develop future engineering leaders is one that industry partners and potential students are expecting us to meet. Yet this challenge comes at a time of dwindling budgets, higher enrollments, and more rigorous research expectations. Many of us feel as if our hands are tied - we know the need, and feel the urgency, yet realize we are ill-prepared to act. To see action, we need individual commitment, surrounded by institutional support, toward a global need. This leaves us with a central question: How do we do more with less? 
In The Courage to Teach, Parker Palmer explores an approach to educational transformation by engaging in deep inquiry of fundamental questions of what, how, why, and who (Palmer 1998). We often start out with content and curriculum - the what that is being taught. If we dig a bit deeper, we begin to consider pedagogical structures - the how we are teaching the what. Occasionally, we may ask why we are teaching what we teach. Rarely, however, do we get to the point of reflecting and sharing the personal values present in our teaching and learning endeavor - the root questions of who are we as teachers, and equally important, who are our students as learners? These three elements - curricular content (what), pedagogical structure (how), and personal values (why and who) - serve as the basis for a model for this paper that can help frame our actions toward more intentional leadership development for undergraduate students.

\section{A Changing Landscape - A Case for Why We Need to Act}

Globalization, generational shifts in the workplace, more flexible organizational structures, and increasingly complex problems require us to rethink how we cultivate, identify, and sustain leaders of the future (NAE 2004). Societal needs for sustainable energy sources, upgrades to our decaying infrastructure, access to clean water, and affordable health care are just a few of the many global challenges engineering leaders will be called upon to resolve throughout their careers with a stronger sense of urgency than we currently face. The technologies already exist to address many of these needs. What we lack, however, are leaders at all levels who are able to integrate their technical expertise into non-technical arenas to work cross-disciplinarily, cross-functionally, and cross-culturally, to bring technological ideas to life in a relevant context and on a broader scale.

The NAE committee who authored the "Engineer of 2020" (NAE 2004) referred to this need when they defined several "Aspirations for the Engineer of 2020" including a call for us to aspire to a future of engineering that includes professionals who, "assume leadership positions...in the making of public policy and in the administration of government and industry", and to, "effectively recruit, nurture, and welcome underrepresented groups to its ranks". The guiding principles of the NAE report also include keeping, "pace with technological innovations", and expanding our capacity to appropriately contribute to an, "increasingly diverse and multidisciplinary" global community. More recently, in February 2012, the President's Council of Advisors on Science and Technology published a report that included three imperatives: 1) Improve the first two years of STEM education in college, 2) Provide all students with the tools to excel, and 3) Diversify pathways to STEM degrees (President's Council 2012).

Without a doubt, these are challenging goals under any circumstances. Our current divisive political climate and uncertain economic outlook make this an even more daunting task. To help frame a course of action at an institutional level, we must address a fundamental question: Amidst continually decreasing budgets for public higher education, how can we respond to a growing need to educate future engineering leaders by:

1. increasing and diversifying our enrollments,

2. expanding our curriculum beyond familiar terrain of technical expertise to engage cross-disciplinary synergies we don't yet fully understand, 
3. shifting our pedagogical framework to be more effective, current, and relevant to a more diverse student body, and

4. maintaining the rigor and quality of world class educational experiences for all students?

There is no magic bullet solution that meets these four challenges. No single event, institution, or individual led us to these challenges, and no single solution is going to resolve them. Rather, there are multiple avenues to explore and many points of intervention that can collectively make a difference. To borrow from a baseball analogy, if we wait for the homerun hitter to clean the bases with a grand slam, we are committing three troublesome errors. First, we are relegating the responsibility to someone else. Second, we are assuming that there is a single "homerun" solution that can do it all. Finally, we are deferring action until a later time, when the time to act is now. We all can do something - today. But what and how?

To paraphrase Albert Einstein, we cannot address the problems of tomorrow with the same approaches we used to create them. It is critical to note that both the NAE and the President's Council highlight the importance of diversifying our discipline. Historically in the United States, the engineering discipline, "has been nourished principally by drawing from a white male population" (NAE 2004). Looking to the future, the opportunities to address the problems we will face, and the body of work to be done, requires us to expand our discipline to be more inclusive of, and welcoming to, a more diverse group of talented individuals. Additionally, we must begin to tip the balance toward an integrated model that strives to educate the whole person - technical and non-technical - such that our graduates are prepared to be leaders who can address the global needs of the future that differ from what was needed when many of us completed school.

As educators, we do not leave technical skills development to chance, hoping that students will pick them up along the way or learn them from someone else. But, it is fairly common for us to approach leadership skills development as if it is something that can be deferred until later in student's career, or "outsourced" to another department, school, or organization. Sometimes, we adopt the "osmosis" model and hope students pick up the requisite leadership skills simply by struggling their way through college. Solid technical skills will get students into the door of a career. From there, however, it is often their leadership skills that will limit or expand their career opportunities and success.

This paper is based on the premise that starting with ourselves as educators, we need to reconsider the way we individually and collectively think about, embrace, and intentionally develop engineering leaders of the future. For some students, our current approach is a viable model for their success. No doubt, today we have many highly successful engineering leaders in our discipline. For other students, however, in particular those who hail from underrepresented demographics, we are doing them and our discipline a disservice by presuming that they will find their way amidst a learning environment that has been documented to be ineffective, unwelcoming, and even hostile or threatening to them (Steele 2010). Thus, we leave the leadership of our disciplines in the hands of the select few for whom the traditional approach has worked. This homogenization of our discipline perpetuates our current cycle and restricts our ability as a discipline to advance toward an increasingly complex, global, and intermingled future. 


\section{An Institutional Pathway Forward}

To develop a strong cohort of future engineering leaders, our institutions need to engage, support, and exhibit leadership at all levels. We need a compelling and coordinated vision from the top, supported by mid-level champions across campus and enacted by committed individuals in- and out of- the classroom. We all have a place at the table and a voice in the conversation for taking good intentions and moving them to action.

The University of Wisconsin-Madison has a long-standing institutional history and tradition of graduating strong leaders, including more Peace Corps and Teach for America volunteers than most any other university in the country, and more leaders of major corporations than any university in the country (Berquam and Brower 2010). In an attempt to better understand why, recent campus-wide efforts have focused on defining the "Wisconsin Experience" - a set of core institutional principles and practices that help cultivate a campus culture of holistic education that can provide a framework for more intentional leadership development efforts (Berquam and Brower 2010). Our decentralized campus and faculty governance structure make it difficult to embrace a single model or coordinated approach. We often find that we recreate the wheel in many pockets of campus, at times competing with each other for resources and participants. But we all have in common a desire to create learning experiences that are inclusive, rigorous, and engaging for our students to help prepare them to be leaders with a vibrant future.

The common language of the "Wisconsin Experience" provides the UW-Madison with a framework to more consistently explicate our culture, and to work cross-disciplinarily and cross-functionally toward common educational goals. A set of Essential Learning Outcomes (ELO) provides an overall picture of what students need to prepare for the $21^{\text {st }}$ century challenges (AAC\&U, 2007). Broadly speaking, the ELO's include:

1. Knowledge of human cultures and the physical and natural world

2. Intellectual and practical skills

3. Personal and social responsibility, and

4. Integrative learning

To meet these ELO's, a set of High Impact Practices (HIP) provide a list of opportunities for experiential learning that can be adapted for individual courses (Kuh, 2008, AAC\&U, 2007). Together, these ELO's and HIP's have been instrumental in moving toward unifying our campus efforts to broaden the core of "usual suspects" involved in leadership development all without institutional mandates that dictate the specifics of how. This is the type of top level institutional vision required to solidify a path forward.

Our College level first-year enrollment numbers reflect a national trend where the number of potential engineering students continues to increase (ASEE 2012). UW-Madison has seen a 42\% increase from 2005-2010 (Romero 2011), and our students are entering with more robust leadership experiences and higher expectations for continued leadership development. Higher enrollments and expectations, coupled with decreasing budgets poses a pedagogical challenge to advance our teaching by continuing to connect, engage, and explore new terrain with our students. Our College of Engineering administration has 
supported leadership development via student organizations, small enrollment courses, internships and co-ops, and numerous workshops, seminars, guest speakers, and activities (Doll et al. 2009). In recent years the College has made strides toward a more integrative model that brings together curricular, extra-curricular, and professional development activities to provide students with more integrated leadership development experiences.

But an institution-wide vision and college level support will remain theoretical unless and until individual faculty in the classroom make the commitment to initiate change. This is precisely where we focused our efforts when we created an experimental course, "Core Competencies for Engineering Leaders". This course addressed student and industry expectations for formalized leadership development and offered pressure relief for other high-enrollment introductory core Engineering courses that are currently over capacity. After three successful semesters, the course is poised for continuation and growth to scale up to meet the increasing demands. The remainder of the paper will focus on the creation, evolution, and future growth plans for the course, and will point to lessons learned that can assist in adaptation for other institutions.

\section{Evolution of a Course - Design and Structure}

The authors of this paper, with feet planted in academia, industry, and our community, observed a gap in our curriculum that needed to be addressed. Industry was looking to hire engineers with a set of skills and experiences we felt our undergraduates were not adequately receiving. We also perceive a growing need for our students to have global awareness and community involvement to be better able to act as stewards of the engineering discipline throughout their careers. In response to this need, we developed a course to address two main objectives intended to develop future leaders by:

1. Raising awareness, appreciation, and knowledge of leadership to help make informed and intentional choices about professional life;

2. Engaging in experiential service learning to develop and apply critical leadership skills.

In 2008, with funding from the College of Engineering's "Engineer of 2010" program to fund innovative curricular projects, we developed a Junior/Senior level leadership development course for students holding leadership positions in student organizations. Student feedback from four semesters of this course told us that they would have benefited from this course had it been offered earlier in their college career - ideally their first year.

In response to this feedback, with the support of the Pieper Foundation (srpieperfamilyfoundation.com), and under the leadership of an endowed professorship for Servant Leadership, we created and launched a pilot course in Fall 2011 for 25 incoming first year students. One course enrollment slot was open during each summer orientation session until the course filled. Quickly we had a waiting list of additional students wanting to enroll, so in Spring and Fall 2012, the enrollment cap expanded to 35. Each time the course filled to capacity. As we write this paper, we are considering feasible models to gradually expand the enrollment such that we can meet the demand while maintaining the 
integrity, rigor, and intimacy of a small group learning experience - a central feature of the course.

The course content is framed by the Social Change Model of Leadership Development (Astin 1996) and a commitment to Servant Leadership (Keith 2008). It is based on the premise that leadership is not simply a place of positional authority. Rather, leadership is a process that can be learned, and includes a responsibility to act in service to others rather than a role of exerting control over others. Everyone has the potential to be a leader, but it takes intentional development - a purpose this course is designed to meet.

The 15-week semester is sequenced in four themes intended to engage students in four phases of development: 1) understand historical context and landscape of leadership, 2) develop a framework for action, 3) apply skills to move from concept to action, and finally 4) reflect on what they learned to craft a plan of action for ongoing future growth and development. Their movement through these four themes is reflected in our pedagogical approach that advances course content by increasing the complexity of course assignments throughout the semester. Our method of delivery and engagement also progressively puts more responsibility and autonomy on the students as the semester progresses.

The course structure is designed to build a learning community where small group learning experiences serve as a central feature. Learning community development requires more than simply putting students together in groups and sending them on their way to do their work. The groups are designed to be as diverse as possible across multiple dimensions to enhance student learning (Page 2007). Our approach is based on the four primary principles of learning communities as defined by Brower and Dettinger (1998):

1. Shared learning and discovery,

2. Meaningful interactions,

3. Connections to out-of-class activities,

4. Inclusive learning environments.

To meet the learning community challenge of maintaining small group experiences on a large campus, we engaged a group of upper level undergraduate Student Assistants (SA's) to help teach the course. We hire enough SA's to maintain a student:instructor ratio of 7:1, an optimal group size for meaningful and inclusive exchange of diverse ideas (Zander and Cartwright 1968). The challenge of scaling up for even larger enrollments will be further addressed later in the paper.

The course also integrates ample time for individual reflection such that the performance and learning of more introverted students is not compromised. As Susan Cain writes, "we should actively seek out symbiotic introvert-extrovert relationships, in which leadership and other tasks are divided according to people's strengths and temperaments", (Cain 2012).

\section{"Who" Are We as Teachers and Who Are Our Students?}

Many faculty primarily trained as researchers face the "imposter syndrome" - the feeling that we do not know what we are doing when we step into the role as teachers (Clance 1985). 
Ambrose, et al. (2010) write, "Principles of learning apply to instructors as well because, when it comes to teaching, most of us are still learning. Teaching is a complex activity, and yet most of us have not received formal training in pedagogy." This sobering insight leads us to ask questions about ourselves and our students. What do our students need and what do they want (these are often times not the same)? Who are we, as teachers, and how can what we have to offer fulfill the needs and wants of the students?

As teachers, we are expected to have the answers and are not accustomed to publicly acknowledging when we are struggling through our own learning. Throughout the course development process, we often found examples when we needed to once again become learners ourselves.

As an example, we realized we needed to appropriately embrace technology and social media as a viable means of engaging with students. Our familiar approach largely relied on face-to-face in-class interactions. What role could, and should, technology play in the course to enhance learning? To what extent do we pursue hybrid or blended learning opportunities as detailed in Garrison and Vaughan (2008)? Do we move mini-lectures to online recordings to view outside of class? Do we create a course Facebook page? Tweet with our students? Hold online "office hour" chats? These, and many other options, are currently under consideration as the course continues to evolve and we continue to learn.

We also found areas where we had to set aside our personal preferences because they were out of alignment with, or not fully inclusive of, the diverse student needs. In the spirit of Robert Greenleaf's model of Servant Leadership "to serve first" before aspiring to lead (Greenleaf 1977) we needed to step back and understand how this course could serve our students. Our work with the Center for the First Year Experience (newstudent.wisc.edu) strengthened the course by solidifying the way we integrated course content with the process of their first year transition to college (Ward-Roof 2010). The course was brought to life as we grounded it in the student experience, informed by real world applications, and framed by academic theories and models.

The course requires a lead instructor with experience in industry and the classroom, and the ability to connect with students without appearing to be too far removed from the realities of their lives. Where there were gaps in real world experience, we filled them with campus, community, and industry guest speakers, always mindful of avoiding the pedagogical model of disconnected "talking heads" popping in and out to cover a variety of topics. Where we found disconnects from the student experience, we relied on the SA's and students to bring their wealth of relevant, creative, thoughtful, and engaging student experiences into class to learn from each other.

At times it was not easy or comfortable turning over control of the course to learn from the students and SA's. Stepping out of our roles as teachers to once again assume that of a learner runs counter to the traditional faculty culture, yet may be exactly what we need to do to connect with our students. In David Damrosch's book about reconceptualizing the university, he writes, "If genuine academic reform is to occur, this community needs to be more fully understood and then creatively reconceived" (Damrosch 1995). With this in mind, we now turn to the question, how can we creatively reconceive our approaches to teaching? 


\section{"What" Are We Teaching, and "How" Are We Teaching It?}

One approach to the question of "how" that resonates with engineers is the concept of backwards design (Wiggins and McTighe, 2006) a design approach adapted for curricular reform. Backwards design starts with the end goals in mind and works "backwards" toward the pedagogical practices and content needed to reach these goals. As an institution, the UW-Madison is committed to the broad set of Essential Learning Outcomes (ELO) as the starting point, and to a to a set of High Impact Practices (HIP) that provide an array of engaging and actionable options to align learning activities with course goals. Sandwiched in the middle are assignments and forms of assessment that serve as mechanisms to help students demonstrate their learning gains (Figure 1).

Essential Learning

Outcomes (ELO): What

will students know, value,

and be able to do?
Assessment of Learning:

How will students

demonstrate their

learning?
High Impact Practices

(HIP): What will we do to

facilitate their learning?

Fig. 1. Essential Learning Outcomes (ELO) and High Impact Practices (HIP)

Applying these steps to the leadership course, we started with the four overall objectives of engineering education listed in the introduction: 1) increase diversity, 2) expand our curriculum, 3) shift our pedagogical framework, and 4) maintain the rigor and quality of education. Specific course objectives are for students to reflect on, and demonstrate knowledge of:

1. A personal vision for their professional future and the spectrum of career opportunities available,

2. How their strengths, leadership potential, and development needs can help them achieve their personal vision,

3. The leadership roles that engineering professionals can play in service to a breadth of technical, social, political, environmental, economic, and global issues,

4. How to access resources to assist ongoing leadership development beyond this course.

We also developed a set of experiential course objectives for students to be able to:

5. Comfortably and professionally communicate directly with peers, practicing engineers and adult professionals,

6. Apply and reflect on the "Seven C's" of the Social Change Model (Astin 1996) through engaging as Servant-Leaders (Keith 2008) in a stewardship service project, 
7. Apply teamwork and leadership skills necessary to embrace individual differences and help groups collaborate on shared aims and values,

8. Use new skills, tools, and insights to advance ideas from concepts to action,

9. Craft an action plan for future leadership development.

Students enter college at different levels of ability for each of these objectives, but they all begin with a basis. Rather than further stratifying students into predetermined tracks based on their entry point, we wanted to engage all students and help them advance their learning, regardless of where they started. Bloom's Taxonomy (Bloom et al. 1956) widely used over the years to define levels of the cognitive domain of learning, provided a basis to consider how to engage students at all levels of development. Since its original inception, Bloom's model has been critiqued as being too sequential and simplistic, and exclusive because it was develop by and from the experiences of colleges-aged male students (Hogsett 1992). Hogsett's critique is valid, and provides a more comprehensive insight into the subtleties and complexities of our cognitive development. Yet there are parts of Bloom's original model that remain useful. Statistician George Box's famous saying that, "All models are wrong, but some are useful" is particularly salient here. With Hogsett's critique, Box's invitation to take what is useful, and Anderson and Krathwohl's work that further refined Bloom's work with nineteen specific cognitive processes (Anderson et al. 2001) we have a useful framework to determine learning objectives and learning activities for the course. Table 1 illustrates how the refined model of Bloom's Taxonomy was coupled with the primary assignment types to addressed the various levels of learning.

\begin{tabular}{|l|l|l|l|l|l|l|}
\hline \multirow{2}{*}{$\begin{array}{l}\text { Assignment } \\
\text { Type }\end{array}$} & \multicolumn{5}{|c|}{ Modified Bloom's Taxonomy (Anderson, Krathwohl, and Bloom, 2001) } \\
\cline { 2 - 7 } & Remember & Understand & Apply & Analyze & Evaluate & Create \\
\hline $\begin{array}{l}\text { Reflections } \\
\text { and written } \\
\text { homework }\end{array}$ & $\begin{array}{l}\text { Recognize } \\
\text { Recall }\end{array}$ & $\begin{array}{l}\text { Interpret } \\
\text { Summarize } \\
\text { Compare } \\
\text { Explain }\end{array}$ & & $\begin{array}{l}\text { Differentiate } \\
\text { Organize }\end{array}$ & $\begin{array}{l}\text { Check } \\
\text { Critique }\end{array}$ & \\
\hline $\begin{array}{l}\text { Course } \\
\text { project }\end{array}$ & & & $\begin{array}{l}\text { Execute } \\
\text { Implement }\end{array}$ & & \\
\hline $\begin{array}{l}\text { Out-of-class } \\
\text { activities }\end{array}$ & & & $\begin{array}{l}\text { Execute } \\
\text { Implement }\end{array}$ & & & $\begin{array}{l}\text { Plan } \\
\text { Generate } \\
\text { Produce }\end{array}$ \\
\hline $\begin{array}{l}\text { In-class } \\
\text { attendance \& } \\
\text { participation }\end{array}$ & & $\begin{array}{l}\text { Interpret } \\
\text { Exemplify } \\
\text { Summarize }\end{array}$ & $\begin{array}{l}\text { Execute } \\
\text { Implement }\end{array}$ & $\begin{array}{l}\text { Differentiate } \\
\text { Attribute }\end{array}$ & $\begin{array}{l}\text { Checking } \\
\text { Critique }\end{array}$ & Generate \\
\hline
\end{tabular}

Table 1. Modified Bloom's Taxonomy Aligned with Assignment Type

Reflective writing, a useful professional skill to develop (Brookfield 1995; Schön 1983) is used as a primary mechanism to help students meet the course objectives. The course incorporates a combination of in-class real-time brief reflective writings, weekly unrefined homework submissions, and deeper, more comprehensive writing assignments to help students process, synthesize, and analyze their learning. 
An example of how the generic table above can be applied to each of the specific course objectives is shown in Table 2 for Objective \#7, "Apply teamwork and leadership skills necessary to embrace individual differences and help groups collaborate on shared aims and values". This completed table illustrates how each assignment type addresses some (but not all) levels of Bloom's taxonomy, and how collectively all assignments fulfill all levels.

\begin{tabular}{|c|c|c|c|c|c|c|}
\hline \multirow[t]{2}{*}{$\begin{array}{l}\text { Assignment } \\
\text { Type }\end{array}$} & \multicolumn{6}{|c|}{$\begin{array}{l}\text { Modified Bloom's Taxonomy (Anderson and Krathwohl, 2001) } \\
\text { [Applied to Learning Objective\#7: Developing Teamwork Skills] }\end{array}$} \\
\hline & Remember & Understand & Apply & Analyze & Evaluate & Create \\
\hline $\begin{array}{l}\text { Reflections } \\
\text { and written } \\
\text { homework }\end{array}$ & \multicolumn{2}{|c|}{$\begin{array}{l}\text { Weekly informal reflections, } \\
\text { and periodic formal written } \\
\text { homework assignments about } \\
\text { group process }\end{array}$} & & \multicolumn{2}{|c|}{$\begin{array}{l}\text { Weekly informal } \\
\text { reflections, and periodic } \\
\text { formal written homework } \\
\text { assignments about group } \\
\text { process }\end{array}$} & \\
\hline $\begin{array}{l}\text { Course } \\
\text { project }\end{array}$ & & & \multirow{2}{*}{$\begin{array}{l}\text { Project team } \\
\text { formation \& } \\
\text { execution to } \\
\text { implement } \\
\text { out-of-class } \\
\text { project }\end{array}$} & & & $\begin{array}{l}\text { Project team } \\
\text { formation \& } \\
\text { project } \\
\text { creation }\end{array}$ \\
\hline $\begin{array}{l}\text { Out-of-class } \\
\text { activities }\end{array}$ & & & & & & \\
\hline $\begin{array}{l}\text { In-class } \\
\text { attendance \& } \\
\text { participation }\end{array}$ & & \multicolumn{5}{|c|}{$\begin{array}{l}\text { In-class discussions to understand connections between, and application of, } \\
\text { course content to project creation and implementation. Analysis and } \\
\text { evaluation come from lessons learned through implementation and peer } \\
\text { review. }\end{array}$} \\
\hline
\end{tabular}

Table 2. Table 1 Applied to Specific Example of Group Work

\section{Student Data: Early Signs of Success and Suggestions for Improvement}

We are currently working to obtain student consent to be able to more fully report on detailed student feedback and assessment results (see Lessons Learned and Future Work section below). At this point, we can report aggregate data from the end of semester student online survey that had a $100 \%$ response rate. The survey combined Likert scale rankings as well as open-ended free response questions. The results from the questions most salient to this paper are reported below.

\section{Question}

1. I have many opportunities to discuss course content directly with my instructors.

2. I get help from my instructors quickly when I need it.

3. I feel comfortable discussing course content with my instructors.

4. My instructors care very much whether I learn the course content.

5. I have opportunities to work with other students.

6. I feel comfortable discussing course content with other

\begin{tabular}{|c|}
\hline $\begin{array}{c}\text { Percent who agree o } \\
\text { strongly agree } \\
97 \%\end{array}$ \\
\hline $97 \%$ \\
\hline $97 \%$ \\
\hline $97 \%$ \\
\hline $94 \%$ \\
\hline $94 \%$ \\
\hline
\end{tabular}


students.

7. Interacting with other students greatly increases my learning. $\quad 79 \%$

8. My interest in this class is very high. $\quad 67 \%$

9. I feel like I am learning the course content successfully. $91 \%$

These data show that we have been successful in bridging the gap that frequently exists between students and instructors. Students feel like the instructors are accessible, caring, and responsive to their needs. Interestingly, in the free response portion of the survey, the students make no distinction between the role of the faculty member and that of the student assistants. The student comments strongly indicate that the SA model of instruction was appreciated, effective, and valuable. This is further validated by the responses to Question \#9 that shows $91 \%$ of the students feel as if they were successfully learning the course material. The SA model is a scalable model that will be further explored in the next section.

A brief mention of areas of improvement is warranted here and will be further expanded in the Lessons Learned and Future Work section below. First, although 79\% of the students found that student interactions greatly increased their learning (Question \#7), it is significantly lower than the positive responses regarding interactions with the instructors. Peer interactions are a significant element of the course structure, yet $21 \%$ of students are not greatly benefiting from their interactions with their peers. This is an area to further explore to determine ways to increase the benefit of peer-to-peer interactions.

Furthermore, the student responses to Question \#8 indicate that fully one-third of the students do not find the course highly interesting. Since the purpose of this course is to engage first year students in developing their leadership skills and their understanding of engineering as a discipline, we need to learn more about why these students are not finding it interesting. Regardless, the responses to the rest of the survey indicate that the vast majority of students are engaged with the instructors and feel as if they are learning the material. This will undoubtedly help them make informed choices about their major.

\section{Growing Pains: Issues of Scale and Content}

Three primary issues emerge when we consider scaling up the course to accommodate larger enrollments: time, money, and quality of learning. The small group, flexible, writingintensive model presented thus far works well for 35 students. How can we scale up to accommodate increasing enrollment and maintain the intimacy of a small group feel without exceeding our limited course budget and over-extending the faculty? And, how can we provide a meaningful, grounded, and foundational learning experience about leadership that helps launch students toward continued learning and application throughout their college experience (and ultimately into their career)? We found the SA model as a viable model to address all three of these challenges.

\section{Issues of Time and Money}

To scale up, faculty need to release our felt need to be the central source and channel for content delivery. We need to be open to, and rely on, the Student Assistants to facilitate the small group learning process and provide them with experiences as peer teachers and leaders. We invested time for SA orientation up front (4 hours) and throughout the semester (45 minutes-1 hour per week) to emphasize grading, student-led discussions and group work. 
This investment allowed SA's and students to focus on discussing and relating to the course content rather than being bogged down by the dynamics of dysfunctional groups.

The grading was equally shared amongst the faculty member and all SA's, thus reducing the overall load and time commitment on the faculty member. As illustrated in the data above, this did not have a detrimental effect on the student's learning or their perceptions of the role of the faculty member. Rather, it proved to be mutually beneficial. Freshmen students and SA's alike had an engaging learning experience, and it helped bridge the age and "relevance" gap between the faculty and first year students by offering a one-on-one senior peer instructor model.

Over time, this model can become self-sustaining as we build in a succession model by inviting students who took the course during their first year to return in future years to teach as SA's. This self-sustaining approach also reduces the SA orientation needs and maintains consistency and quality through the years. The course is currently too young to have fully implemented this succession model, though one current SA was a student during the pilot offering. Her involvement in the course for multiple offerings has proven to be valuable.

A strong team of SA's serves as a leverage point for growth as the faculty role becomes one of setting the overall content and direction of the class, facilitating the progression of the class at the large group level, and mentoring the SA's to lead their small groups. The SA's gain first hand real world professional experience working with a faculty mentor to help them manage their small groups, provide peer review for the students, and guide them in their role as a "Project Manager" to work with students on their semester projects. They also practice communication skills while leading mini-presentations and facilitating small group discussions in class. SA's are also seen as role models for the first year students and engage with their "boss" as they are expected to provide formative feedback about the class and the faculty member.

The SA model proved to be financially viable. SA's are paid undergraduate hourly wage for approximately six hours per week. The faculty member counts this course as part of their normal teaching load. We are considering options for SA's to use their teaching experience as a project for a yet-to-be-developed advanced leadership seminar they can opt to take for credit in lieu of receiving payment. This credit-based approach to working with SA's further sustains the course as a financially viable and scalable model, builds in succession planning, continuity and quality of instruction, and provides a path for leadership development for students throughout their undergraduate experience.

\section{Issues of Quality of Learning}

With a commitment to release the need to be the single instructor and sole source of information and content, it becomes easier to find ways to facilitate a process of laying a common direction for all, then turning it over to students to make meaning. Rather than assuming that students are clean slates when it comes to leadership, we assume that each student has a set of experiences upon which we can build. Today's students are more globally aware than our students were just 10 years ago and are better connected to the vast resources available at their fingertips. What is often missing, however, is a maturity for information literacy to discern useful, relevant, and legitimate information. To address the issue of engineering content coverage, personal relevance, and information literacy, we 
remain flexible to build lessons around current events that reinforce the core content of leadership development.

For example, during the Fall 2011 semester, Time magazine published an article about the failure of the Nano-car - an automobile manufactured in India, marketed throughout the Far East and Europe (Thottam 2011). The short article highlighted the combination technical, cultural, political, and economic issues that led to the product failure. The story provided an opportunity to explore a case study that connected real life engineering issues with recent classroom discussions of leadership skills, culture, personal communication styles, and benefits of diverse groups for brainstorming. Using a brief in-class self-assessment on information processing styles (brainstormer, problem solver, doer, and processor), we grouped students by like-style and gave them the short, densely packed article to read during class. We then asked them to brainstorm a list of all factors that led to failure of the car (at least 10 were cited in the article). As expected, the brainstormers jumped right in and developed a long list of factors on the white board. The processors took their time to think and plan before committing any words to the board. The doers and problem solvers wanted to skim the article and jump in to solve the technical problem before listing all the contributing factors.

In the middle of their group process, we paused to highlight a few key points. The purpose of the activity was not necessarily to fully understand the problems and solutions for the Nano car. Rather, the purpose was do demonstrate, through a relevant and current engineering example, how their individual and group tendencies play out in a semi-realistic workplace setting (e.g. brainstorming solutions for an engineering problem) and make direct connections to course content.

Another example of pausing during the regular flow of class to take advantage of a leadership learning moment took place when we experienced a failure of classroom communications. Nearly half the class missed changes to the details and due date for an assignment that was announced in class. During class the following week, we explored the situation as a case study and connected it to lessons on communication breakdowns. (The changes were announced last week. What happened such that half of the class did not respond to the announcement?) Abstract and theoretical models of communication breakdowns were brought to life by making direct and real time connections between course content, an event that they were experiencing that related to their life, and consequences of poor communication.

\section{The "Not-So-Hidden" Curriculum}

Both of the examples above required the instructor to go "off script" to engage students. The benefits of doing so can be considered part of the hidden curriculum, or "lessons which are learned, but not openly intended" (Martin 1983). Though not explicitly stated, all four of the challenges mentioned at the outset of this paper are addressed by these "hidden lessons". We expand our curriculum by shifting our pedagogical framework such that the rigor and quality of learning is not compromised.

This approach also creates new entry points through which students can approach the course 
lessons that helps diversify our enrolled student population - rather than a "one size fits all" approach. Doing so addresses the achievement gap - discrepancies in our educational institutions that tend to unintentionally benefit majority populations over underrepresented minorities (KewalRamani et al. 2007). The underlying issues and root causes that lead to the achievement gap are deeply embedded in our society and have a long history that will not be resolved overnight, or within a single course. But that does not mean we should not address this critical issue whenever and wherever we are able. For this course, we used the engineering concept of "universal design" to address a common critique that efforts to close the achievement gap amount to preferential treatment for minorities at the expense of majority students. Universal design fundamentally states that there are effective designs that can benefit all, and may disproportionately benefit those who are most in need (think sidewalk curb cuts intended to help those in wheelchairs, but also assist others in maneuvering from the sidewalk to the street level). This same concept can be used in educational design for learning experiences that are good for everyone, but may disproportionately benefit those most in need.

There is also a hidden agenda to address naysayers who believe that leadership development on a larger scale cannot be done amidst tight budgets and dwindling resources. The existence of a scalable model that engages students early in their college career and involves alumni, industry, and the community can help get the next rung of faculty and administrators on board who may currently be resistant to change or hesitant to get involved. The existence of this type of course offering can help with alumni and industry relations by providing campuses with something tangible to point to that says, "this is what we're doing to address the need for leadership development". Good community, alumni and industry relations benefits fundraising, engagement in career fairs and hiring practices, and overall positive community public relations.

Finally, let's not lose sight of the impact on the students. A course like this, in their first year shows institutional commitment and embeds the importance of leadership from the start to help students establish critical skills that will carry with them throughout their college and professional careers. We have existence proof that iterative change can happen without wholesale curriculum redesign - though that may be what is ultimately needed.

\section{Lessons Learned and Future Work}

The specific lessons learned are too numerous to fully cover here, so they are presented below as five broad lessons.

1. Engage in teaching as a research endeavor (CIRTL 2012).

2. Forge campus and community partnerships with functional roles.

3. Situate tradition within the context of diverse contemporary and future needs.

4. Make a large campus feel small.

5. Commit to implementation despite real and perceived barriers.

Teaching as a Research Endeavor

The first lesson learned is to anticipate success by creating a plan that fulfills our professional obligation to disseminate successful models for adaptation by others. Engage early with your Institutional Review Board (IRB) or Human Subjects Research Committee 
so that you can use course evaluations, student work, and other student data to share with others. We are in the process of doing that now and are not yet able to fully report on our findings. At this time, we can only report in aggregate our general observations without more specific student data. As reported above, however, we can confidently say that students have made gains in all of the stated course objectives. We have also discovered other unanticipated benefits that support the course structure and pedagogy as a successful model worthy of continuing.

\section{Campus and Community Partnerships}

Fundamentally, we learned that there is a need and a demand for student leadership development in many forms. When each of these multiple forms exists in isolation, we fragment the student experience and deep learning and application becomes more of a challenge. To the extent possible, we recommend nurturing collaborations and partnerships with multiple units on campus and the broader community to bring a richer experience to our students. Doing so helps broaden and connect the student experience, ground it in reality, and forge unanticipated connections. For example, throughout the course, we had defined, functional, and purposeful course connections with the following campus and community organizations:

- College of Engineering Student Leadership Center (slc.engr.wisc.edu)

- College of Engineering Career Services (ecs.engr.wisc.edu)

- College of Engineering Student Orientation and Registration (newstudent.wisc.edu/soar)

- Center for Leadership Involvement, Adventure Learning Program, and Leadership Certificate (cfli.wisc.edu)

- The Morgridge Center for Public Service (morgridge.wisc.edu)

- Center for First Year Experience (newstudent.wisc.edu)

- Multiple local engineering firms

- Dozens of campus alumni

- Multiple campus student organizations

Initially, forging these connections took significant time and energy. However, we embraced it as an investment in the future, and now that they are established, the maintenance is minimal. We are reaping benefits beyond or initial expectations and find that we are contributing to the future of our students, the future of advancing the mission of our campus, and more broadly for our society.

\section{Balance Tradition with Diverse Contemporary Needs}

The course content must balance a respect and understanding of tradition while embracing contemporary and future needs. It must be relevant, real time, and interesting from the student's diverse perspectives. The diversity represented by any group of students is profoundly larger than a single instructor, and must be intentionally included as a core construct of the course. This proved to be true with both the SA's as instructors/learners, and with the first year students as learners/peers. Both the students and the faculty benefit from releasing control in the classroom to allow the students to take ownership of their learning. Some of the most insightful learning came from students, so the faculty member must be open to allowing that to happen. 


\section{Make the Large Feel Small}

Especially at large public universities, we need to find ways to make a large campus feel small. The vast majority of a first year student's academic life exists outside the classroom amidst a swarm of humanity, often times much larger than their hometown and high school experience. As faculty members, we need to find ways to stay connected with student life outside of class and decrease the barriers that exist between us and our students. We need to be seen as human, approachable, and empathetic.

At the University of Wisconsin-Madison, we are fortunate to have access to the Wisconsin Collaboratory for Enhanced Learning, WisCEL (wiscel.wisc.edu). WisCEL is, "an innovative approach to learning that combines deliberate choices of physical environment including multi-use spaces, technology that supports both peer-collaboration and self-paced learning, and software which provides immediate feedback to students on assignments and exams and allows increased instructor time with students." (WisCEL, 2012). If a space like WisCEL is not available on your campus, consider space at the student union, or even with small groups in a department conference room. The key point is to get out of a traditional classroom to open up options for a different kind of thinking, learning, and teaching that more closely resembles a workplace environment.

\section{Commit to Making it Happen}

Several influential leaders throughout history have made the call for change by saying, "If not us, who? If not now, when?" It can be difficult to overcome the inertia of inaction because of perceived barriers. We can always find a reason to not do something (time, money, lack of support, uncertainty, etc.). It is also easy to sit on the sidelines and hope someone else acts in our stead.

\section{Continued Improvements and Future Work}

The mid-course and end-of-semester evaluations, and final student projects indicate that the first three offerings of the course have been successful. Yet the nature of this course, the evolving role of leadership in engineering, and the growing demands for enrollment point to several areas for future work and development.

We need to expand our efforts to continue leadership development beyond the first year experience. To that end, we will explore ways to more intentionally connect with students on internships and co-ops as they are gaining real world experience. As the course expands and requires a larger pool of SA's, we can explore an upper level cohort model for an advanced level leadership seminar for the SA's. We also want to remain connected with our students after graduation by building in more points of interaction with alumni once they enter the job market.

Course activities will continue to evolve as we experiment with new ideas. Field trips to local engineering companies, expanded connections with campus and community organizations for service projects, and the growing spectrum of creative classroom activities from SA's will be integrated into future semesters. With this growth comes a need for a more defined course infrastructure. Online resources, banks of readings and course manuals for leading various course activities, and moving some boiler plate lecture material to an online environment are all avenues to pursue to create a course knowledge base and 
infrastructure for the future. Finally, a more formalized approach to educational research is needed to show baseline data and demonstrate impact.

\section{Adapting to Other Institutions}

Every institution has its own culture complete with opportunities and obstacles. The details above provide specifics for how we planted seeds for success at our institution and plan to grow. The guidelines below provide some touchstones to consider when adapting to your institution.

1. Embrace the existing culture. For many institutions, curricular reform to consider leadership development may not be a top priority. Your starting point may be student organizations, co-ops and internships, campus partnerships, or perhaps faculty development. Regardless of the starting point, an understanding of the current realities of your institutional culture is critical to knowing how to work within it as you advocate for further involvement in leadership development.

2. Start small and grow. Successful places to start will require leverage points with high potential for short-term impact. Our starting point was a pilot course for 25 first year students. We knew there was interest, we had top-level support, and we had a need to relieve enrollment pressures for other introductory courses. Your starting point may differ, but start somewhere.

3. Allow multiple entry points for involvement. Provide ways that individuals can engage in your efforts with varying levels of involvement including advisory, advocacy, planning, and central involvement in implementation. If structured well, everyone interested can find a way to contribute at any level of involvement.

4. Work with the "choir". Understand that some people may resist or have no interest in getting involved, so start with those who are receptive. Ask yourself, "Who are the $10 \%$ committed core I can rely on?" Then find ways they can be actively engaged. Do not ask for, or expect much from uninterested individuals, but also be cautious to not be exclusionary. You may be surprised at who is interested in getting involved if you genuinely invite them and have a role they can play in the effort.

5. Collaborate with others beyond the "usual suspects". Where you have a need you cannot fulfill yourself, engage with others on campus and the community. Realize that each person will have their own personal motivators, level of readiness to engage, and ability to commit, so meet them where they are and co-create a mutually beneficial role.

6. Seek frequent and honest feedback. Be intentional about requesting feedback in multiple formats and from a broad spectrum of individuals. Then, be responsive to what you learn. This may require a thick skin, but will ultimately result in a more inclusive and sustaining initiative.

\section{If Not Us, Who? If Not Now, When?}

There are tangible and substantial ways engineers can engage in addressing the grand challenges of our time if they have the requisite leadership skills. For readers who feel this work is a distraction from the core technical curriculum of engineering, we ask that, at a 
minimum, you do not create obstacles for others who want to engage in this work. For readers who remain uncertain or unable to dedicate the energy necessary to take on a new course like this, we invite you to consider other ways you can engage in leadership development that are less time intensive and fit your current situation. For those of you inspired to take action, we hope this paper has provided you with some insight into how to take the next steps.

As educators, we can model for our profession what we would like to see on a global scale. Technical skills, individual motivation, and good intentions are necessary, but not sufficient conditions to have the scale of effort we need to make progress. We also need intentional leadership development to move from idea and intent to implementation and impact. For those of you motivated by this challenge, developing a course like the one presented in this paper can provide a next step in the journey. Whether your are an administrator looking to initiate change, a faculty member searching for ways to broaden your influence, an alumni looking to give back to your school, or a student looking to jump start your career, we all can have a role in these efforts to make a difference in our world.

\section{Bibliography}

AAC\&U liberal education and America’s promise (LEAP). (2007). < http://www.aacu.org/leap/> (Jun. 21, 2012).

ASEE. (2012). Undergraduate enrollment continues its upward trend.

Ambrose, S. A. (2010). How learning works: Seven research-based principles for smart teaching. JosseyBass, San Francisco, CA.

Anderson, L. W., Krathwohl, D. R., and Bloom, B. S. (2001). A taxonomy for learning, teaching, and assessing : A Revision of Bloom's Taxonomy of educational objectives. Longman, New York.

Astin, H. S. (1996). "Leadership for social change.” About Campus, 4-10.

Berquam, L. \&, and Brower, A. M. (2010). The Wisconsin Experience and the essential learning outcomes.

Bloom, B. S., Engelhart, M. D., Krathwohl, D. R., and Masia, B. B. (1956). Taxonomy of educational objectives: The classification of educational goals. D. McKay Co., Inc., New York.

Brookfield, S. (1995). Becoming a critically reflective teacher. Jossey-Bass, San Francisco.

Brower, A. M., and Dettinger, K. M. (1998). "What 'is' a learning community? Toward a comprehensive model." About Campus, 3(5), 15-22.

Cain, S. (2012). Quiet: The power of introverts in a world that can't stop talking. Crown Publishers, New York.

CIRTL. (2012). “Teaching-as-Research.” <http://cirtl.wceruw.org/pillars_TAR.html> (Jun. 21, 2012).

Clance, P. R. (1985). Impostor phenomenon: Overcoming the fear that haunts your success. Peachtree Publishers. 
Damrosch, D. (1995). We scholars: Changing the culture of the university. Harvard University Press, Cambridge, Massachusetts, 225.

Doll, N., Jackson, A., Lafayette, M., and Russell, J. (2009). Engineering alumni leadership survey report. University of Wisconsin-Madison.

Garrison, D. R., and Vaughan, N. D. (2008). Blended learning in higher education: Framework, principles, and guidelines. Jossey-Bass, San Francisco.

Greenleaf, R. K. (1977). Servant leadership: A journey into the nature of legitimate power and greatness. Paulist Press, New York.

Hogsett, C. (1992). “Women's ways of knowing Bloom's Taxonomy.” Feminist Teacher, 7(3), 27-32.

Keith, K. M. (2008). The case for servant leadership. Greenleaf Center for Servant Leadership, Westfield, IN.

KewalRamani, A., Gilbertson, L., Fox, M., and Provasnik, S. (2007). Status and trends in the education of racial and ethnic minorities. Washington, DC.

Kuh, G. (2008). High Impact Practices: What they are, who has them, and why they matter. Association of American Colleges and Universities, Washington, DC.

Martin, J. (1983). What should we do with a hidden curriculum when we find one? (H. Giroux and D. Purpel, eds.), McCutchan Publishing Corporation, Berkeley, California, 122-139.

NAE. (2004). The engineer of 2020: Visions of engineering in the new century. The National Academies Press, Washington, DC.

Page, S. E. (2007). The difference : How the power of diversity creates better groups, firms, schools, and societies. Princeton University Press, Princeton.

Palmer, P. J. (1998). The courage to teach: Exploring the inner landscape of a teacher's life. The Courage To Teach, Jossey-Bass, San Fransisco, 199.

President's Council of Advisors on Science and Technology. (2012). Engage to excel: producing one million additional college graduates with degrees in science, technology, engineering, and mathematics: A report by the President's Council of Advisors on Science and Technology.

Romero, M. (2011). Improving Access to Undergraduate Advising. College of Engineering, University of Wisconsin-Madison.

Schön, D. A. (1983). The reflective practitioner : How professionals think in action. Basic Books, New York.

Steele, C. (2010). Whistling Vivaldi: And other clues to how stereotypes affect us. Issues of our time, W.W. Norton \& Company, New York.

Thottam, J. (2011). “The little car that couldn’t.” Time Magazine, Business 1-4.

Ward-Roof, J. A. (2010). Designing successful transitions: A guide for orienting students to college. Columbia, South Carolina: University of South Carolina, National Resource Center for The First-Year Experience and Students in Transition.

Wiggins, G. P., and McTighe, J. (2006). Understanding by design. Pearson Education, Inc., Upper Saddle River, N.J. 
WisCEL (Wisconsin Collaboratory for Enhanced Learning). (2012). $<$ http://www.wiscel.wisc.edu/> (Jun. 21, 2012).

Zander, A. F., and Cartwright, D. (1968). Group dynamics: Research and theory. Harper \& Row, New York. 